\title{
Estudos anatômicos de folhas de Espécies de Plantas Daninhas DE GRANDE OCORRÊNCIA NO BRASIL. V - Leonurus sibiricus, Leonotis nepetaefolia, Plantago tomentosa E Sida glaziovii ${ }^{1}$
}

\author{
Anatomical Studies of Leaves in Weed Widely Largely Occurring in Brazil. V-Leonurus \\ sibiricus, Leonotis nepetaefolia, Plantago tomentosa and Sida glaziovii
}

PROCÓPIO, S.O. ${ }^{2}$, FERREIRA, E.A. ${ }^{3}$, SILVA, E.A.M. ${ }^{4}$, SILVA, A.A. ${ }^{5}$ e RUFINO, R.J.N. ${ }^{3}$

RESUMO - O objetivo desta pesquisa foi estudar a anatomia foliar das espécies de plantas daninhas Leonurus sibiricus (rubim), Leonotis nepetaefolia (cordão-de-frade), Plantago tomentosa (tanchagem) e Sida glaziovii (guanxuma-branca) e, assim, obter melhor entendimento das barreiras à penetração dos herbicidas e, conseqüentemente, fornecer subsídios à busca de estratégias de manejo para superar esses obstáculos. As folhas expandidas do terceiro ao quinto nó foram coletadas de plantas no campo; destas folhas foram obtidas três amostras da região central, com aproximadamente $1 \mathrm{~cm}^{2}$, as quais foram utilizadas em estudos da estrutura e clarificação e em observações em microscópio eletrônico de varredura (MEV). L. sibiricus é uma espécie hipoestomática, e as demais espécies avaliadas são anfiestomáticas. As principais barreiras foliares potenciais à penetração de herbicidas constatadas em $L$. sibiricus foram a alta densidade tricomática e a ausência de estômatos na face adaxial. Já em relação a L. nepetaefolia, alta densidade tricomática, grande espessura da cutícula da face adaxial e baixa densidade estomática na face adaxial foram os principais obstáculos potenciais detectados. P. tomentosa apresentou como possiveis barreiras foliares à penetração de herbicidas o alto teor de cera epicuticular, a alta densidade tricomática e a grande espessura da cutícula de ambas as faces. Alta densidade tricomática e baixa densidade estomática na face adaxial foram os possiveis obstáculos constatados nas folhas de S. glaziovii.

Palavras-chave: cutícula, cera epicuticular, estômato, tricoma, feixes vasculares.

\begin{abstract}
The objective of this research was to study the leaf anatomy of the weed species Leonurus sibiricus, Leonotis nepetaefolia, Plantago tomentosa and Sida glaziovii to acquire a better understanding of the barriers each species imposes upon herbicide penetration, thus supporting the search for strategies to overcome these obstacles. Completely expanded leaves from the third to the fifth nodes of the plants were collected in the field. Three samples of approximately $1 \mathrm{~cm}^{2}$ were taken from the central portion of the leaves of each species to be used in the studies of structure and clarification as well as observations through a scanningelectron microscope (SEM). L. sibiricus is the only hypostomatic species, while the others are amphistomatic species. The main leaf barriers observed against herbicide penetration in L. sibiricus were high trichomic density and stomata absence in the adaxial side; in L. nepetaefolia, the barriers were high trichomic density, high cuticle thickness in the adaxial side and low stomatic density in the adaxial side, whereas in $\boldsymbol{P}$. tomentosa the barriers were high content of epicuticular wax, high trichomic density and high cuticle thicknesses. High trichomic density and low stomatic density in the adaxial side were the herbicide barriers observed in the leaves of $\mathbf{S}$. glaziovii.
\end{abstract}

Key words: cuticle, epicuticular wax, stomata, trichome, vascular bunches.

Recebido para publicação em 22.4.2002 e na forma revisada em 12.12.2003.

2 Doutorando em Fitotecnia, Dep. de Fitotecnia da Universidade Federal de Viçosa - UFV, 36571-000 Viçosa-MG <procopio@alunos.ufv.br>; ${ }^{3}$ Mestrando em Botânica, Dep. de Biologia Vegetal da UFV, <ealves.ferreira@bol.com.br>; ${ }^{4}$ Prof. do Dep. de Biologia Vegetal da UFV, <esilva@mail.ufv.br>; ${ }^{5}$ Prof. do Dep. de Fitotecnia da UFV, <aasilva@mail.ufv.br>; ${ }^{3}$ Acadêmico de Agronomia, estagiário do Dep. de Biologia Vegetal da UFV, <rufino@homenet.com.br>. 


\section{INTRODUÇÃO}

O conhecimento dos mecanismos de penetração dos herbicidas nos tecidos vegetais é fundamental para o sucesso do controle químico das plantas daninhas. Os herbicidas podem penetrar nas plantas através de suas estruturas aéreas (folhas, caules, flores e frutos) e subterrâneas (raizes, rizomas, tubérculos, etc.), de estruturas jovens e, também, pelas sementes (Silva et al., 2000). Contudo, são as folhas o principal órgão das plantas daninhas envolvido na penetração de herbicidas aplicados em pós-emergência.

A morfologia das plantas, principalmente das folhas, influencia a quantidade do herbicida interceptado e retido, porém são as características anatômicas destas que praticamente determinam a facilidade com que esses produtos serão absorvidos (Hess \& Falk, 1990).

Em superficies foliares que possuem baixo teor de cera epicuticular (ex.: Beta vulgaris), as gotas da calda herbicida pulverizada cobrem grandes áreas, produzindo vários depósitos nas depressões acima das paredes anticlinais. Quando o mesmo herbicida é aplicado do mesmo modo sobre uma folha com altos niveis de cera epicuticular (ex.: Cynodon dactylon), ocorre menor porcentagem da superficie foliar coberta com o herbicida, reduzindo, assim, o número de células em contato com o produto (Hess \& Falk, 1990).

As folhas apresentam vários níveis de desenvolvimento de tricomas e glândulas, que podem variar com a espécie. Abutilon theophrasti, por exemplo, possui tricomas simples e complexos e Chenopodium album possui alta densidade de tricomas glandulares na epiderme adaxial. Em conseqüência disso, nesta espécie as células da epiderme propriamente dias podem se encontrar totalmente escondidas (Hess \& Falk, 1990). Tricomas presentes na superficie foliar podem interceptar gotas pulverizadas, impedindo que estas alcancem a epiderme propriamente dita. Até mesmo quando os tricomas são simples e ocorrem em baixa densidade verifica-se a aderência de gotas sobre eles (Ricotta \& Masiunas, 1992). A eficiência da absorção de herbicidas pelos tricomas e a translocação destes para as células epidérmicas ainda são parcialmente desconhecidas (Hess \& Falk, 1990). Entretanto, de acordo com Hull (1970), pequena absorção pode ocorrer via tricomas. Hess \& Falk (1990) afirmam que na maioria dos trabalhos realizados por diversos autores observa-se relação negativa entre a aderência dos herbicidas nos tricomas e a eficácia destes produtos.

Quanto à cutícula, esta é a principal via de absorção dos herbicidas aplicados em pósemergência, sendo o seu conhecimento de importância fundamental nos estudos de absorção (Devine, 1990). O uso de surfatantes siliconados tem contribuído para a quebra da tensão superficial da calda de pulverização na folha, ocasionando assim maior espalhamento do produto e permitindo que os estômatos passem a ter também importante papel na penetração dos herbicidas. Segundo Audus (1976), a tensão superficial máxima para que ocorra fácil penetração da calda aplicada nos estômatos é de 30 dinas $\mathrm{cm}^{-2}$. Outro fator ligado à penetração dos herbicidas pelos estômatos é que a cutícula sobre as células-guarda parece ser mais fina e mais permeável (menor teor de cera epicuticular), constituindo-se numa barreira menos rígida à penetração de herbicidas (Hess \& Falk, 1990). Segundo estes autores, esta característica é importante, pois a maioria das espécies de plantas daninhas apresenta estômatos sobre as superficies adaxial e abaxial (anfiestomáticas).

No entanto, Silva et al. (2000) e Velini \& Trindade (1992) relatam que na maioria destas plantas os estômatos se localizam na face abaxial das folhas (hipoestomáticas), confirmando os resultados observados por Meyer et al. (1973), os quais, realizando contagens do número de estômatos em 39 espécies, verificaram que 16 eram anfiestomáticas e o restante, hipoestomáticas. Também observaram que nas anfiestomáticas o número de estômatos na face adaxial era normalmente inferior ao da face abaxial. É importante lembrar que, em pulverizações agrícolas, a dificuldade de as gotículas atingirem a face abaxial é grande; conseqüentemente, acredita-se que a importância da absorção pelos estômatos desta face seja menor (Silva et al., 2000). Outro fator que sugere pequena importância dos estômatos na absorção de herbicidas é o fato de estes, em vários horários do dia, encontrarem-se fechados, inclusive em aplicações noturnas. Contudo, Taylor et al. (1980) observaram que 
os estômatos foram a principal via de penetração do herbicida bentazon em folhas de Chenopodium album.

A cutícula recobre todas as células da epiderme da planta e atua como interface entre o corpo da planta e o ambiente, realizando a proteção e a prevenção da perda de água dos tecidos vegetais (Bukovac et al., 1990). Ela é também importante barreira à entrada de microrganismos e agroquímicos, inclusive herbicidas. Herbicidas que diferem em estrutura e polaridade atravessam com maior ou menor dificuldade a cutícula. O mecanismo exato de penetração ainda não é conhecido para todos os produtos, mas admite-se que os compostos não-polares sigam a rota lipofilica e os compostos polares, a rota hidrofilica (Silva et al., 2000). De acordo com os mesmos autores, supõe-se que os herbicidas lipofilicos se solubilizem nos componentes lipofilicos da cutícula e se difundam através desta. Já em relação aos herbicidas hidrofilicos, admite-se que a cutícula tenha estrutura porosa, que se mantém hidratada, dependendo das condições ambientais, sendo a água de hidratação da cutícula a rota de penetração destes herbicidas. Outra possivel rota de absorção dos herbicidas polares, citada por Velini \& Trindade (1992), são os filamentos de pectina, que podem cruzar praticamente toda a cutícula; desde que hidratados, eles podem atuar como via de transporte desses produtos.

Leonurus sibiricus apresenta folhas com acentuado heteromorfismo, sendo lobadas com lobos arredondados em plantas novas e profundamente lobadas com lobos lanceolados e ápice agudo em plantas maiores, bem como limbo flácido e nervuras proeminentes na face dorsal (Kissmann, 1999). As folhas de Leonotis nepetaefolia nas partes baixas da planta são longo-pecioladas e têm limbo de formato ovalado ou ovalado-deltóide, com base atenuada e ápice agudo ou obtuso com margens distintamente crenadas, enquanto na parte superior as folhas são menores, de formato lanceolado e curtamente pecioladas (Kissmann, 1999). Plantago tomentosa possui folhas basais, em roseta, podendo se apresentar na horizontal ou eretas; o limbo é elíptico lanceolado, com base atenuada e margens inteiras ou com alguns dentes irregulares (Kissmann, 1999). As folhas de Sida glaziovii são simples, alternas, ocorrendo a distâncias regulares desde a base do caule, com limbo de formato geral ovalado, podendo ser suborbicular ou sub-rômbico, sendo a base geralmente cordada e o ápice obtuso ou arredondado e a margem crenado-serrilhada (Kissmann, 1999).

Objetivou-se neste trabalho estudar a anatomia foliar de quatro espécies de plantas daninhas de grande ocorrência no Brasil, visando melhor entendimento sobre as barreiras impostas por cada espécie à penetração dos herbicidas aplicados em pós-emergência, bem como o desenvolvimento de estratégias para superar esses obstáculos.

\section{MATERIAL E MÉTODOS}

A plantas daninhas avaliadas foram: Leonurus sibiricus (rubim) - Labiatae, Leonotis nepetaefolia (cordão-de-frade) - Labiatae, Plantago tomentosa (tanchagem) - Plantaginaceae e Sida glaziovii (guanxuma-branca) Malvaceae.

As folhas foram coletadas de três plantas de cada espécie de ocorrência espontânea no campus da Universidade Federal de Viçosa. De cada planta foi coletada uma folha do terceiro ao quinto nó, quando estas estavam completamente expandidas. As folhas coletadas foram armazenadas diretamente em FAA 50 e transportadas ao laboratório de Anatomia Vegetal do Departamento de Biologia Vegetal.

Em cada folha, por espécie, foram obtidas três amostras na região central, com aproximadamente $1 \mathrm{~cm}^{2}$, utilizadas para: a) estudos da composição estrutural, b) clarificação e c) observações em microscópio eletrônico de varredura (MEV).

\section{a) Estudo da composição estrutural da folha}

As amostras foram fixadas durante 24 horas em vácuo, em mistura de álcool etílico a $70 \%$, ácido acético e formol (FAA 70), na proporção de 9:0,5:0,5, respectivamente. Após a fixação, foram desidratadas em uma série etílico-butílica progressiva, embebidas em parafina histológica $\left(\mathrm{PF} 48-54^{\circ} \mathrm{C}\right.$ ) e emblocadas em mistura de parafina histológica e cera na proporção de 8:1 v/v. Seções de 10 a $13 \mu \mathrm{m}$ foram obtidas com um micrótomo rotativo Ultracut - Leica RM-2155 e montadas em 
lâminas histológicas. Depois da desparafinização, os cortes foram corados com fuccina básica e azul-de-astra e montados em bálsamodo-canadá. Foram preparadas lâminas de cortes transversais a fresco, que foram submetidas ao reagente citoquímico Sudam III para caracterização das cutículas. Após seleção, alguns cortes foram fotomicrografados, com auxílio de um fotomicroscópio Olympus AX 70 equipado com acessório fotográfico U-PHOTO (Olympus), e analisados pelo software IMAGE PRO-PLUS. Após 10 medições por corte e por folha, foram determinadas as seguintes espessuras: lâmina foliar, epiderme das faces adaxial e abaxial, parênquimas (paliçádico, lacunoso, homogêneo) e cutícula (adaxial e abaxial). Avaliou-se também a taxa de vascularização foliar das espécies vegetais.

\section{b) Clarificação}

As amostras foram clarificadas em álcool etílico a $70 \%$ e branqueadas com solução de $\mathrm{NaOH}$ a $5 \%$ e em hipoclorito de sódio durante dois a três minutos. Após esta etapa, as amostras foram lavadas e desidratadas em uma série etílica progressiva, coradas com safranina $(1 \%$ de solução aquosa) e azul-de-astra e montadas em bálsamo-do-canadá (Berlyn \& Mikshe, 1976, modificado). Fotomicrografias da epiderme das faces adaxial e abaxial foram feitas em fotomicroscópio Olympus AX 70.

$\mathrm{Na}$ análise dessas lâminas foram calculados o índice estomático, a densidade estomática, o comprimento do ostíolo e a densidade de tricomas nas superficies adaxial e abaxial de cada espécie observada. O índice estomático foi calculado pela razão entre o número de estômatos e o número total de células da epiderme (número de estômatos + células epidérmicas) x 100 .

\section{c) Observações ao Microscópio Eletrônico de Varredura (MEV)}

Parte das amostras das folhas foram fixadas em glutaraldeído a $6 \%$, na temperatura de $4{ }^{\circ} \mathrm{C}$, durante 24 horas, pós-fixadas em tetróxido de ósmio a 3\% na mesma temperatura durante duas horas, lavadas em solução-tampão de cacodilato de sódio e desidratadas em série etílica progressiva até álcool etílico absoluto. Essas amostras foram submetidas ao ponto crítico de dessecamento de $\mathrm{CO}_{2}$ em equipamento CPD 020 Ballers Union, montadas em suporte metálico e cobertas com ouro paládio (Bozzola \& Russell, 1992). O material foliar preparado foi observado e eletromicrografado em microscópio eletrônico de varredura JEOL T-200.

\section{RESULTADOS E DISCUSSÃO}

\section{Leonurus sibiricus}

Esta espécie apresenta lâmina foliar com espessura média de 143,06 $\mu \mathrm{m}$ (Tabela 1, Figura 1). A epiderme é simples, sendo a face adaxial mais espessa em relação à abaxial (Tabela 1). Seu mesofilo é dorsiventral, com o parênquima paliçádico apresentando uma camada de células com espessura média de $63,91 \mu \mathrm{m}$, e a espessura média do parênquima lacunoso é de $57,41 \mu \mathrm{m}$ (Tabela 1, Figura 1). As folhas são hipoestomáticas (presença de estômatos apenas na face abaxial das folhas) (Figura 2), estando os estômatos paracíticos dispostos no mesmo nivel das demais células da epiderme. Tricomas tectores unicelulares não-ramificados e tricomas glandulares multicelulares não-ramificados foram observados nas duas faces (Tabela 3, Figura 2). A cutícula é mais espessa na face adaxial das folhas (Tabela 3). A taxa de vascularização foliar média é de três feixes a cada $590 \mu \mathrm{m}$ de largura da lâmina foliar (Tabela 3).

Tabela 1 - Espessura de componentes foliares das espécies de plantas daninhas estudadas. Viçosa-MG. 2002

\begin{tabular}{|c|c|c|c|c|c|c|}
\hline \multirow[t]{2}{*}{ Espécie vegetal } & Lâmina foliar & $\begin{array}{c}\text { Epiderme } \\
\text { adaxial }\end{array}$ & $\begin{array}{c}\text { Epiderme } \\
\text { abaxial }\end{array}$ & $\begin{array}{c}\text { Parênquima } \\
\text { paliçádico }\end{array}$ & $\begin{array}{c}\text { Parênquima } \\
\text { lacunoso }\end{array}$ & $\begin{array}{l}\text { Parênquima } \\
\text { homogêneo }\end{array}$ \\
\hline & \multicolumn{6}{|c|}{ Espessura $(\mu \mathrm{m})$} \\
\hline Leonurus sibiricus & 143,06 & 13,94 & 6,97 & 63,91 & 57,41 & - \\
\hline Leonotis nepetaefolia & 172,23 & 19,37 & 11,44 & 54,44 & 92,55 & - \\
\hline Plantago tomentosa & 233,09 & 16,39 & 13,91 & - & - & 199,93 \\
\hline Sida glaziovii & 127,23 & 15,46 & 9,97 & 52,00 & 45,53 & - \\
\hline
\end{tabular}



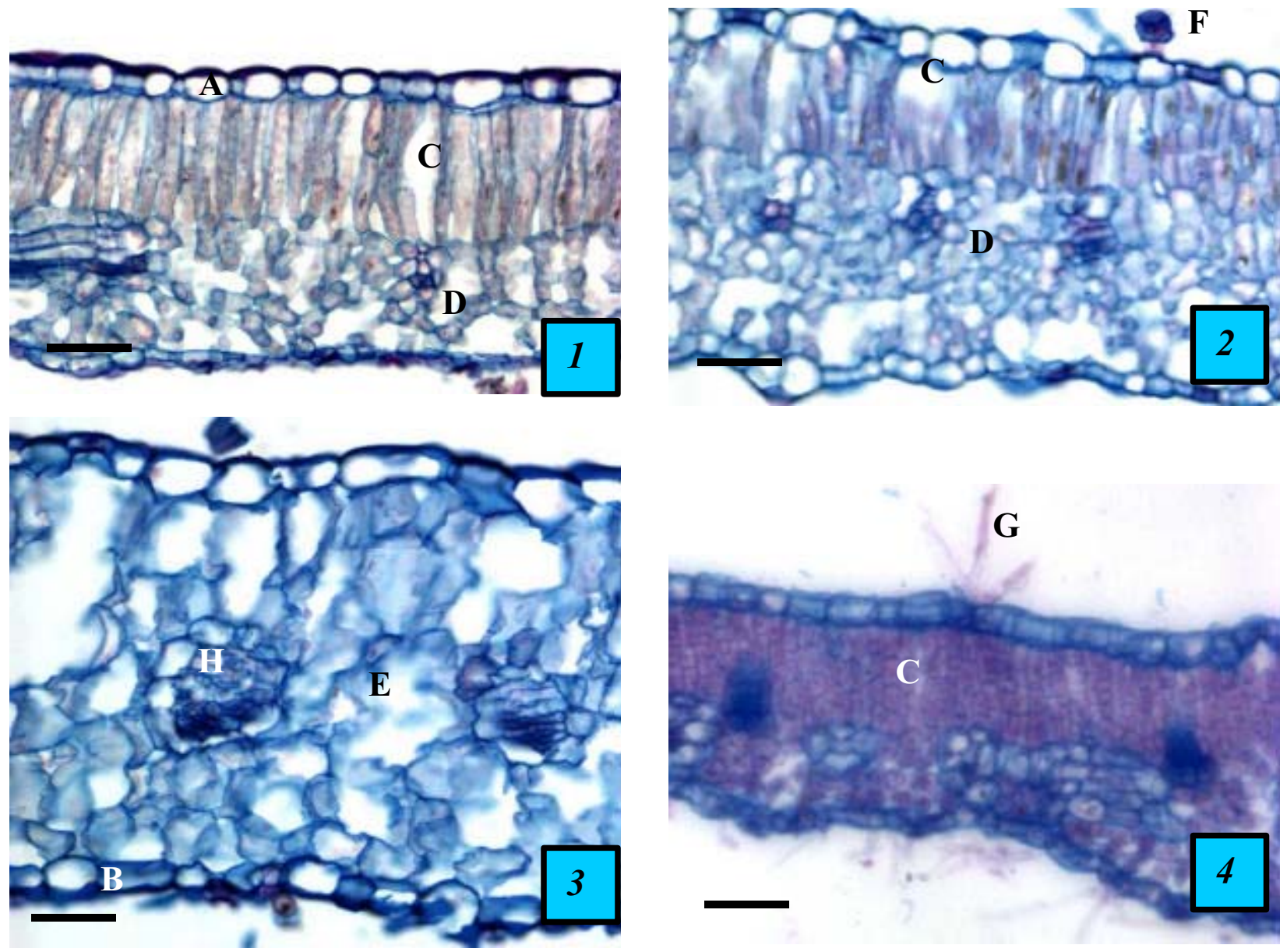

Figura 1 - Seção transversal da lâmina foliar de: 1. rubim (Leonurus sibiricus), 2. cordão-de-frade (Leonotis nepetaefolia), 3. tanchagem (Plantago tomentosa) e 4. guanxuma-branca (Sida glaziovii). A: epiderme abaxial; B: epiderme adaxial; C: parênquima paliçádico; D: parênquima lacunoso; E: parênquima homogêneo; F: tricoma glandular; G: pêlo estrelado (tricoma ramificado); $\mathrm{H}$ : feixe vascular. (Barra $=50 \mu \mathrm{m}$ ).
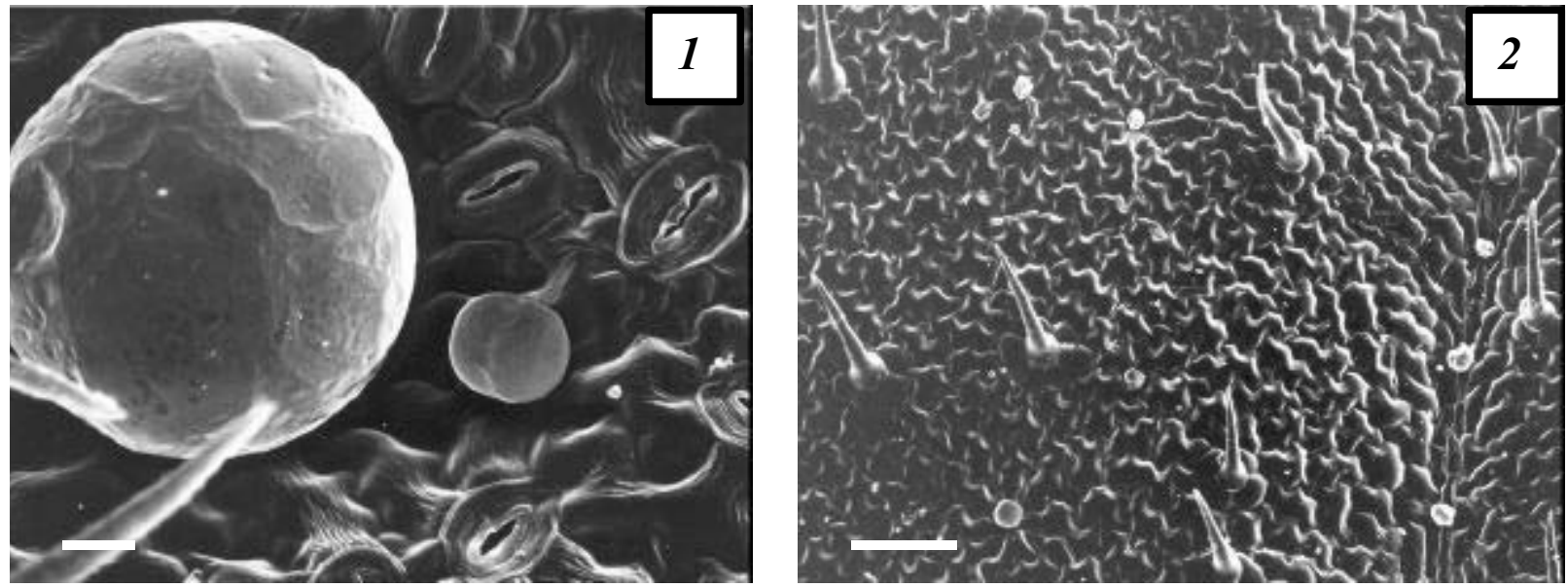

Figura 2 - Superfície foliar das faces abaxial (1) e adaxial (2) de Leonurus sibiricus. (Barra $1=10 \mu \mathrm{m}$ e Barra $2=100 \mu \mathrm{m}$ ). 


\section{Leonotis nepetaefolia}

Apresenta lâmina foliar com espessura média de 172,23 $\mu$ m (Tabela 1, Figura 1). A epiderme é simples, sendo a face adaxial mais espessa em relação a abaxial (Tabela 1). Seu mesofilo é dorsiventral, com o parênquima paliçádico apresenta nas duas camadas de células com espessura total média de $54,44 \mu \mathrm{m}$, e a espessura média do parênquima lacunoso é de $92,55 \mu \mathrm{m}$ (Tabela 1, Figura 1). As folhas são anfiestomáticas (Figura 3); na face adaxial os estômatos estão dispostos no mesmo nível das demais células da epiderme e na face abaxial estes se encontram projetados pouco acima destas e apresentam grandes câmaras subestomáticas. $\mathrm{Na}$ face adaxial os estômatos são diacíticos e na abaxial são anomocíticos - os ostíolos da face adaxial possuem maior comprimento (Tabela 2). Foi verificada a maior presença de estômatos na face abaxial das folhas, sendo esta a espécie que apresentou a maior densidade estomática na face abaxial (Tabela 2). Esta também foi a espécie que apresentou a maior densidade tricomática, tanto de tricomas tectores quanto de glandulares multicelulares não-ramificados, nas duas faces do limbo (Tabela 3, Figuras 1 e 3). A cutícula é mais espessa na face adaxial das folhas (Tabela 3). A taxa de vascularização foliar média é de cinco feixes a cada $590 \mu \mathrm{m}$ de largura da lâmina foliar (Tabela 3).

\section{Plantago tomentosa}

Esta espécie apresenta lâmina foliar com espessura média de 233,09 $\mu \mathrm{m}$ (Tabela 1, Figura 1). A epiderme é simples, sendo a face adaxial mais espessa que a abaxial (Tabela 1). Seu mesofilo é homogêneo, apresentando espessura média de 199,93 um (Tabela 1, Figura 1). As folhas são anfiestomáticas (Figura 4); em ambas as faces os estômatos estão dispostos na mesmo nivel das demais células da epiderme e apresentam grande câmara subestomática. Tanto na face adaxial como na abaxial os estômatos são anomocíticos, e os ostíolos da face abaxial possuem maior comprimento (Tabela 2). Foi verificada a maior presença de estômatos na face abaxial das folhas (Tabela 2). Tricomas tectores multicelulares não-ramificados foram observados nas duas faces das folhas (Tabela 3, Figura 4). A cutícula é mais espessa na face adaxial das folhas (Tabela 3) e apresenta placas de cera epicuticular (Figura 4). A taxa de vascularização foliar média é de três feixes a cada $590 \mu \mathrm{m}$ de largura de lâmina foliar (Tabela 3).

Tabela 2 - Índice estomático, densidade estomática e comprimento de ostíolos das espécies de plantas daninhas estudadas. Viçosa-MG. 2002

\begin{tabular}{|c|c|c|c|c|c|c|}
\hline \multirow[t]{2}{*}{ Espécie vegetal } & \multicolumn{2}{|c|}{$\begin{array}{c}\text { Índice estomático } \\
(\%)\end{array}$} & \multicolumn{2}{|c|}{$\begin{array}{l}\text { Densidade estomática } \\
\text { (estômatos } \mathrm{mm}^{-2} \text { ) }\end{array}$} & \multicolumn{2}{|c|}{ Comprimento do ostíolo $(\mu \mathrm{m})$} \\
\hline & adaxial & abaxial & adaxial & abaxial & adaxial & abaxial \\
\hline Leonurus sibiricus & - & 26,87 & - & 366 & - & 5,40 \\
\hline Leonotis nepetaefolia & 8,69 & 23,04 & 60 & 531 & 14,05 & 11,22 \\
\hline Plantago tomentosa & 17,09 & 22,39 & 100 & 163 & 10,10 & 10,88 \\
\hline Sida glaziovii & 8,79 & 24,90 & 86 & 390 & 6,59 & 9,35 \\
\hline
\end{tabular}

Tabela 3 - Espessura de cutícula, densidade tricomática e vascularização de folhas das espécies de plantas daninhas estudadas. Viçosa-MG. 2002

\begin{tabular}{|l|c|c|c|c|c|}
\hline \multirow{2}{*}{ Espécie vegetal } & \multicolumn{2}{|c|}{$\begin{array}{c}\text { Cutícula } \\
\text { espessura }(\mu \mathrm{m})\end{array}$} & \multicolumn{2}{c|}{$\begin{array}{c}\text { Densidade tricomática } \\
\text { (tricomas } \mathrm{mm}^{-2} \text { ) }\end{array}$} & $\begin{array}{c}\text { Número de feixes vasculares } \\
\text { em } 590 \mu \mathrm{m} \text { de lâmina foliar }\end{array}$ \\
\cline { 2 - 5 } & adaxial & abaxial & adaxial & abaxial & 3 \\
\hline Leonurus sibiricus & 1,35 & 0,72 & 62,40 & 32,60 & 5 \\
Leonotis nepetaefolia & 1,32 & 1,75 & 110,40 & 204,80 & 3 \\
Plantago tomentosa & 1,90 & 2,72 & 3,40 & 4,20 & 5 \\
Sida glaziovii & 1,16 & 0,99 & 33,80 & 25,20 & 5 \\
\hline
\end{tabular}



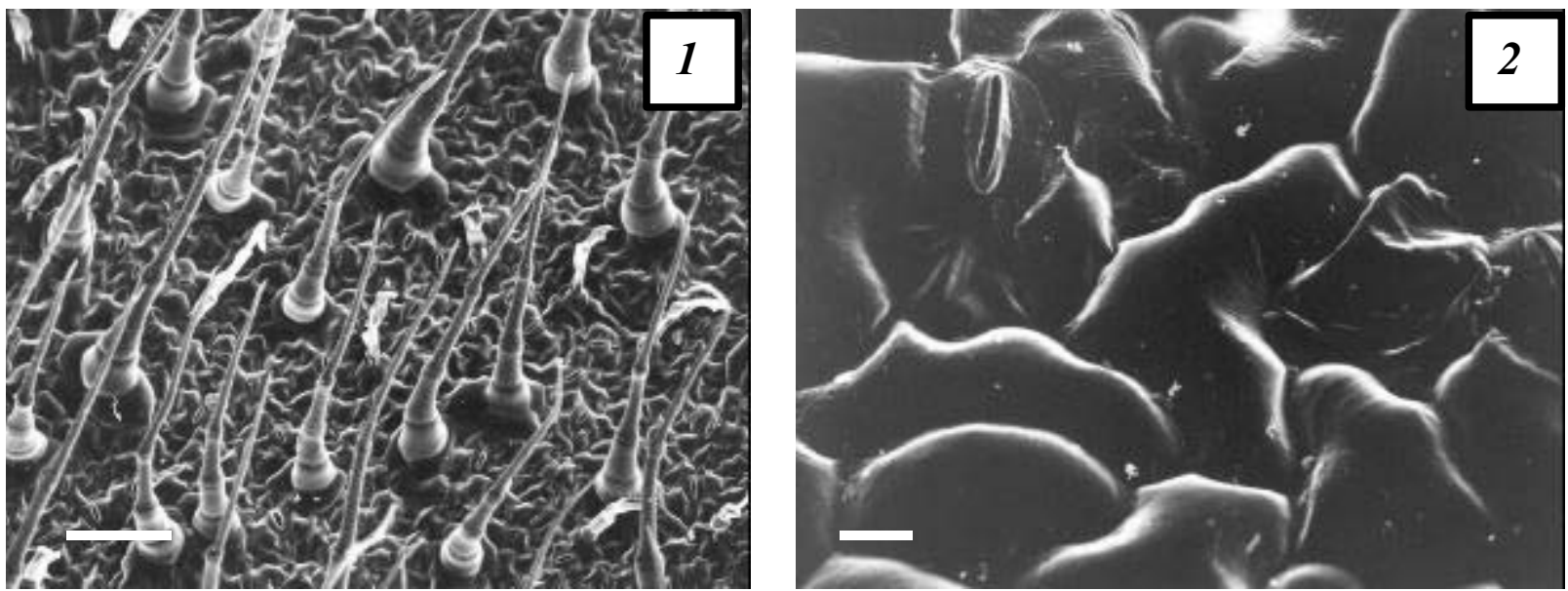

Figura 3 - Superfície foliar das faces abaxial (1) e adaxial (2) de Leonotis nepetaefolia. (Barra $1=100 \mu \mathrm{m}$ e Barra $2=10 \mu \mathrm{m}$ ).
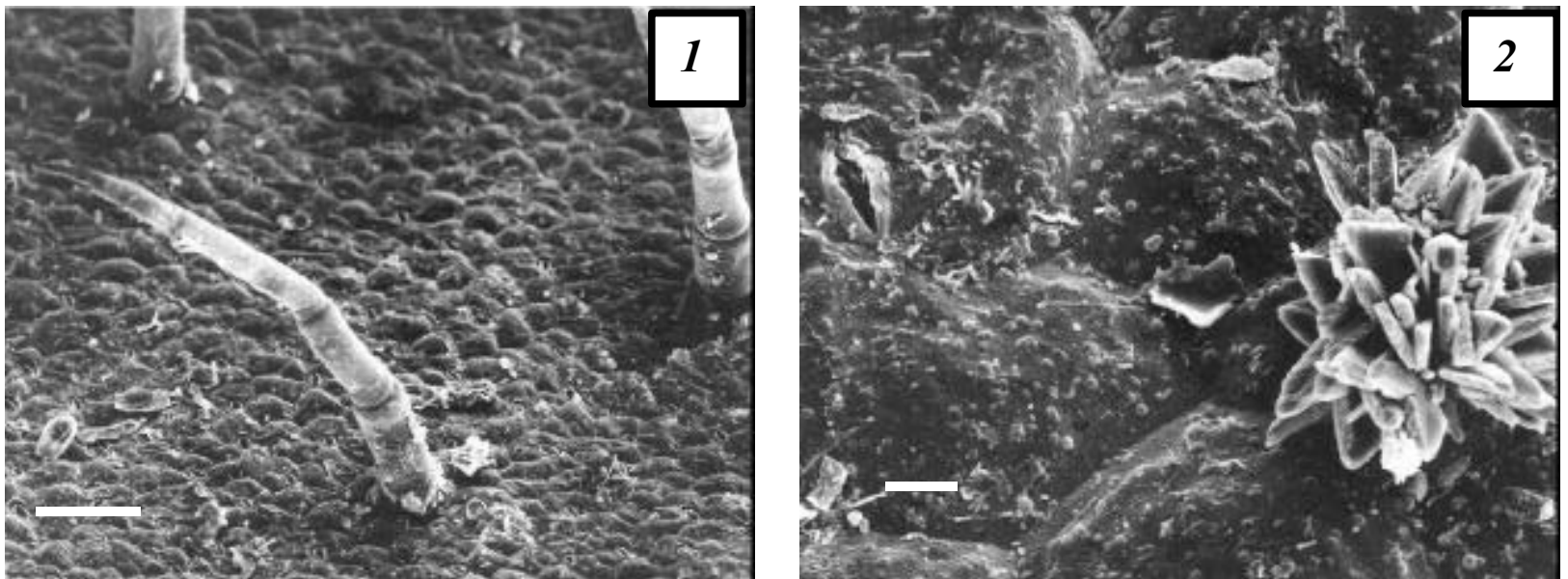

Figura 4 - Superfície foliar das faces abaxial (1) e adaxial (2) de Plantago tomentosa. (Barra $1=100 \mu \mathrm{m}$ e Barra $2=10 \mu \mathrm{m}$ ).
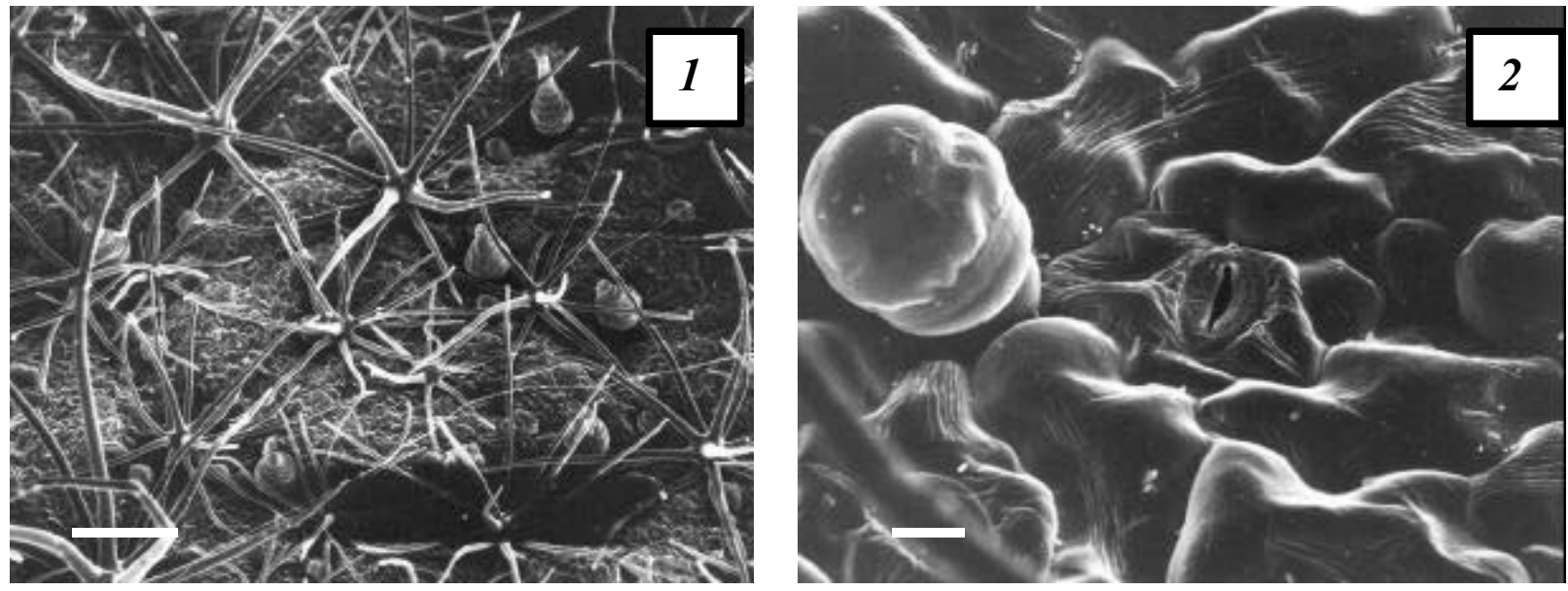

Figura 5 - Superfície foliar das faces abaxial (1) e adaxial (2) de Sida glaziovii. (Barra $1=100 \mu \mathrm{m}$ e Barra $2=10 \mu \mathrm{m}$ ). 
Tabela 4 - Principais barreiras potenciais à penetração de herbicidas em folhas das espécies de plantas daninhas estudadas. Viçosa-MG. 2002

\begin{tabular}{|l|l|}
\hline \multicolumn{1}{|c|}{ Espécie vegetal } & \multicolumn{1}{|c|}{ Principais barreiras foliares à penetração de herbicidas } \\
\hline Leonurus sibiricus & Alta densidade tricomática; ausência de estômatos na face adaxial \\
\hline Leonotis nepetaefolia & $\begin{array}{l}\text { Alta densidade tricomática; grande espessura da cutícula da face adaxial; baixa } \\
\text { densidade estomática na face adaxial }\end{array}$ \\
\hline Plantago tomentosa & $\begin{array}{l}\text { Alto teor de cera epicuticular; alta densidade tricomática; grande espessura das } \\
\text { cutículas }\end{array}$ \\
\hline Sida glaziovii & Alta densidade tricomática; baixa densidade estomática na face adaxial \\
\hline
\end{tabular}

\section{Sida glaziovii}

Esta espécie apresenta lâmina foliar com espessura média de 127,23 $\mu \mathrm{m}$ (Tabela 1, Figura 1). A epiderme é simples, sendo a face adaxial mais espessa em relação à abaxial (Tabela 1). Seu mesofilo é dorsiventral, com o parênquima paliçádico apresentando quatro camadas de células com espessura total média de $52,00 \mu \mathrm{m}$, e a espessura média do parênquima lacunoso é de 45,53 $\mu \mathrm{m}$ (Tabela 1, Figura 1). As folhas são anfiestomáticas (Figura 5); na face adaxial os estômatos estão dispostos no mesmo nivel das demais células da epiderme e, na face abaxial, parte dos estômatos está no mesmo nível destas e outra parte em depressões. Tanto na face adaxial como na abaxial os estômatos são anomocíticos, e os ostíolos da face abaxial possuem maior comprimento (Tabela 2). Foi verificada maior presença de estômatos na face abaxial das folhas (Tabela 2). Pêlos estrelados (tricomas multicelulares ramificados) e de dois tipos de tricomas glandulares multicelulares nãoramificados foram observados em ambas as faces das folhas (Tabela 3, Figuras 1 e 5). Segundo Harr et al. (1991), a espécie Sida spinosa apresenta apenas tricomas tectores não-ramificados e glandulares. A cutícula é mais espessa na face adaxial das folhas (Tabela 3). A taxa de vascularização foliar média é de cinco feixes a cada $590 \mu \mathrm{m}$ de largura de lâmina foliar (Tabela 3). Foi observada a presença de drusas nas células da bainha do feixe vascular.

Um resumo das principais barreiras foliares à penetração dos herbicidas presentes nas espécies de plantas daninhas avaliadas é apresentado na Tabela 4. As principais barreiras foliares potenciais à penetração de herbicidas constatadas em $L$. sibiricus foram a alta densidade tricomática e a ausência de estômatos na face adaxial. Já em relação a L. nepetaefolia, alta densidade tricomática, grande espessura da cutícula na face adaxial e baixa densidade estomática na face adaxial foram os principais obstáculos potenciais detectados. P. tomentosa apresentou como possiveis barreiras foliares à penetração de herbicidas o alto teor de cera epicuticular, a alta densidade tricomática e a grande espessura da cutícula de ambas as faces. Alta densidade tricomática e baixa densidade estomática na face adaxial foram os possiveis obstáculos constatados nas folhas de S. glaziovii.

Com base nas características anatômicas das folhas de $L$. sibiricus, o uso de técnicas de aplicação que facilitem o molhamento da face abaxial das folhas de todas as espécies de plantas daninhas avaliadas, como regulagem da pressão do pulverizador, escolha da ponta de pulverização e uso de surfatantes organossiliconados, deve proporcionar maior penetração dos herbicidas, pois esta face, nestas plantas, apresenta menor espessura de cutícula e maior densidade estomática. A hidratação das placas de cera epicuticular, por exemplo, por meio de irrigação, um dia antes da aplicação do herbicida, o uso de óleos minerais ou vegetais na calda de aplicação e a escolha de formulações mais lipofilicas dos herbicidas podem auxiliar a entrada de herbicidas, principalmente dos produtos que utilizam rota hidrofílica nas 
folhas de $P$. tomentosa que apresentam grande teor de cera epicuticular.

\section{LITERATURA CITADA}

AUDUS, L. J. The physiology and biochemistry of herbicides. 2.ed. New York: Academic Press, 1976. 467 p.

BERLYN, G. P.; MIKSHE, J. P. Botanical

Microtechnique and Cytochemistry. Ames: The Iowa State University Press, 1976. 325 p.

BOZZOLA, J. J.; RUSSELL, L. D. Electron microscopy. Boston: Jones and Bartlett Publishers, 1992. 542 p.

BUKOVAC, M. J. et al. Sorption of organic compounds by plant cuticles. Weed Sci., v. 38, n. 3, p. 289-298, 1990.

DEVINE, M. D. Mechanisms of herbicide absorption and translocation in plants. Weed Sci., v. 38, p. 279-285, 1990.

HARR, J. et al. The leaf surface of major weeds.

Witterswil: Sandoz Agro, 1991. 133 p.

HESS, F. D.; FALK, R. H. Herbicide deposition on leaf surfaces. Weed Science, v. 38, n. 3, p. 280-288, 1990.
HULL, H. M. Leaf structure as related to absorption of pesticides and other compounds. Res. Rev., v. 31, p. 1-155, 1970.

KISSMANN, K. G. Plantas infestantes e nocivas. 2.ed. São Paulo: BASF. 1999. t.2. 976 p.

MEYER, B. et al. Introdução à fisiologia vegetal. 2.ed. Lisboa: Fundação Caloustre Gulbenkian, 1973. 710 p.

RICOTTA, J. A.; MASIUNAS, J. B. Relationship of leaf surface characteristics to acifluorfen tolerance in tomato (Lycopersicon esculentum) and related species. Weed Sci., v. 38, p. 567-572, 1990.

SILVA, A. A. et al. Controle de plantas daninhas. Brasília, DF: ABEAS, 2000. 260 p.

TAYLOR, F. E.; COBB, A. H.; DAVIES, L. G. The effects of bentazon on stomatal behavior in Chenopodium album L. New Phytol., v. 63, p. 369-376, 1980.

VELINI, E. D.; TRINDADE, M. L. B. Comportamento de herbicidas na planta. Épocas de aplicação de herbicidas. In: SIMPÓSIO NACIONAL SOBRE MANEJO INTEGRADO DE PLANTAS DANINHAS EM HORTALIÇAS, 1992, Botucatu, SP. Anais... Botucatu, UNESP, 1992. p. 65-86. 